International Review of Research in Open and Distributed Learning Volume 18, Number 3

May - 2017

\title{
Editorial - Volume 18, Issue 3
}

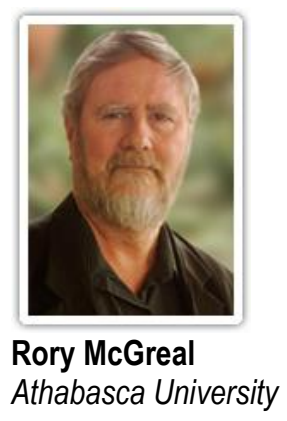

There is a wide variety of research articles in this edition, ranging from connectedness to MOOCs. An article on K12 standards is followed by one on DigitalDNA and one for administrators on talent management. The book review section consists of three reviews led by a book that I co-edited for the Commonwealth of Learning. This is followed by a guide on digital teaching and a text on qualitative research. The final leadership section consists of an editorial and two papers on technology-enhanced learning and adaptive leadership.

The first article "Employing the EPEC Hierarchy of Conditions (Version II) To Evaluate the Effectiveness of Using Synchronous Technologies with Multi-Location Student Cohorts in the Tertiary Education Setting” by Eady, Woodcock, and Sisco investigates the effectiveness of a synchronous platform in teacher training in Australia. They use the EPEC hierarchy for teaching competencies. Their study reinforces findings supporting the effectiveness demonstrated when staff and students are appropriately engaged, noting the importance of the expert tutor. Their results also showed a preference for video conferencing over the use of synchronous learning platforms.

In the second connectedness article, entitled "The Online Student Connectedness Survey: Evidence of Initial Construct Validity," Zimmerman and Nimon, in a higher education setting, examined data from the OSCS for evidence supporting the validity and reliability of the instrument. They also attempted to establish a nomological network between this and other instruments. Validity and reliability were established by the evidence and significant correlations were demonstrated in factors relating to student connectedness.

In another validity and reliability study, this time at the school level, entitled "Improving the K-12 Online Course Design Review Process: Experts Weigh in on iNACOL National Standards for Quality Online Courses," Adelstein and Barbour report on the second phase of an investigation of the United States' iNACOL standards for quality in online K-12 courses. They used expert panels to search the scholarly literature, and then examined the goals and refined the standards. This is an independent panel formed 
because states were adopting online course design standards from advocacy organizations which had not been validated from a research perspective.

"Talent Management Implementation at an Open Distance E-Learning Higher Educational Institution: The Views of Senior Line Managers" is the title of the next article by Erasmus, Naido, and Joubert also from UNISA. They investigate recruiting and retaining talented staff by relying on the perceptions of senior line managers. Using qualitative approach and purposive sampling, researchers interviewed these senior personnel. The analysis revealed a disconnect between the inclusive/developable talent strategy expounded by the university and the actual implementation, which was insular and not integrated with the actual Human Resource policies.

Prototyping has been used effectively in creating new learning environments, starting with design, through implementation and evaluation. As blended learning is becoming the norm in many traditional universities, prototyping can be one way of ensuring a robust implementation. This process is described in this paper by Wang, Quek, and Hu entitled "Designing and Improving a Blended Synchronous Learning Environment: An Educational Design Research.” Implementing four rounds of prototyping in an Asian university, the researcher found that a mixed video conferencing/classroom environment was capable of supporting learning, but not without challenges.

The final two research articles look at MOOCs, focusing on motivation and writing skills. The first of these is authored by Alario-Hoyos, Estévez-Ayres, Pérez-Sanagustín, Kloos and FernándezPanadero, and entitled "Understanding Learners' Motivation and Learning Strategies in MOOCs." The authors argue that dropout rates, which are a traditional measure of course quality, is not a useful measure when evaluating MOOCs. They claim that the diverse participants have a wide range of selflearning skills, and they need to be at a high level to keep pace and attend to course requirements. In particular, time management skills were needed to improve the learning capability of participants. In the second MOOC article, Kwak argues that grammar and text construction should be the focus of academic writing MOOCs. His paper, "Approaches Reflected in Academic Writing MOOCs," examines six such MOOCs looking at the curriculum, the videos and student assignments, finding that they all used traditional models for teaching writing skills.

This issue also includes three book reviews, each of which provides us with specific information for different open and distributed learning research audiences. The first is for those administrators and others who are interested in OER policies, etc. The second is for online teachers and the third is for researchers. The leadership section consisting of an editorial and two papers on leadership will be of interest to those readers who wish to effect meaningful change in their institutions.

Athabasca University

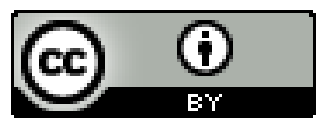

